\title{
O voto de estrangeiros nos países do Cone Sul: Uma análise de direito comparado ${ }^{1}$
}

The foreigners vote at the American Southern Cone countries: A comparative law

analysis

Gustavo Luiz von Bahten²

\section{RESUMO}

O artigo traz uma breve análise comparativa das legislações dos cinco países do Cone Sul (Argentina, Brasil, Chile, Paraguai e Uruguai) a respeito da capacidade eleitoral ativa (direito ao voto) dos estrangeiros residentes nestes países.

Palavras-Chave: Direito ao voto; sufrágio transnacional; Cone Sul.

\begin{abstract}
The article presents a brief comparative analysis of the laws of the five countries of the Southern Cone (Argentina, Brazil, Chile, Paraguay and Uruguay) on the active electoral capacity (right to vote) of foreign residents in these countries.
\end{abstract} Key-words: Right to vote; transnational suffrage; Southern Cone.

\section{Nota Introdutória}

Não há dúvida de que a capacidade eleitoral ativa - o direito ao voto - é pilar fundamental de um Estado Democrático de Direito. De acordo com ROUSSEAU, “o voto é um direito que ninguém pode subtrair aos cidadãos", uma vez que cada indivíduo, sendo parte da coletividade política, é titular de fração da soberania estatal. ${ }^{3}$

Na história constitucional e política recente houve um incremento significativo no número de categorias de indivíduos titulares do direito de votar. ${ }^{4}$ Exempli gratia,

\footnotetext{
${ }^{1}$ Artigo recebido em 06 de maio de 2013 e aprovado para publicação em 07 de setembro de 2013.

2 Advogado, graduado em Direito pela UFPR, mestre pela Universidade de Heidelberg (Alemanha) e PhD pela Universidade de Milão (Itália). Contato: gbahten@vonbahten.com.br

${ }^{3}$ CERQUEIRA, Thales Tácito P.L. de Pádua. Direito Eleitoral Brasileiro. 3a ed. Belo Horizonte: Del Rey, 2004. p. 182. "O sufrágio-direito parte de Jean Jacques Rousseau, para quem, sendo cada cidadão uma parte da coletividade política, e sendo a soberania indelegável, é ele o titular de parte ou fração da própria soberania. Rousseau é muito claro a respeito: 'A soberania não pode ser representada, pois não admite alienação. Ela se expressa pela vontade geral, e esta não admite representantes.' Por isso, o célebre genebrino costumava dizer: 'O voto é um direito que ninguém pode subtrair aos cidadãos.'”

4 GOMES DA SILVA, Paulo Thadeu. Inclusão eleitoral e efetivação dos direitos políticos. In: Temas de Direito Eleitoral no século XXI. Brasília: ESMPU, 2012. p. 49 “(....) esse direito é representado, na história
} 
mulheres, pobres e analfabetos, antes alijados deste direito fundamental, hoje já se encontram - na maior parte das democracias - incluídos no rol daqueles habilitados a escolher seus representantes através do exercício do sufrágio.

0 mesmo, entretanto, não ocorre, em número relevante de países, com os estrangeiros residentes. Muitos Estados ditos democráticos negam aos estrangeiros residentes em seus territórios o direito de sufrágio, não estendendo a eles o direito à capacidade eleitoral ativa. Deste modo, são estes indivíduos excluídos dos processos eleitorais, sendo impedidos de escolher os representantes que irão governar e decidir os rumos das políticas públicas no local em que decidiram fixar residência.

Em um mundo globalizado como o que vivemos, é natural que indivíduos fixem residência em Estado distinto do de sua nacionalidade originária. Esses estrangeiros, via de regra, integram-se às comunidades em que vivem, e sofrem diversas consequências dos atos dos governos locais, seja nos níveis municipal, estadual como federal. Assim sendo, a discussão acerca da capacidade eleitoral ativa dos estrangeiros adquire fundamental importância.

O escopo do presente trabalho é, em uma breve síntese, relatar o tratamento do tema do voto dos estrangeiros nos cinco países do Cone Sul (Argentina, Brasil, Chile, Paraguai e Uruguai), ressaltando as principais semelhanças assim como os traços distintivos das legislações analisadas.

\section{Análise comparativa das legislações dos países do Cone Sul}

\section{Argentina}

De acordo com o texto constitucional argentino, em seu artigo vinte, os estrangeiros gozam de todos os direitos civis dos cidadãos. Todavia, o artigo primeiro do Código Eleitoral (lei 19.945) estabelece que são eleitores nacionais apenas os argentinos natos ou naturalizados. Isto posto, na Argentina os estrangeiros não podem votar em eleições de nível nacional, consequentemente não podendo eleger presidente,

constitucional e política mundial, ao menos na ocidental, pelo ganho paulatino dos direitos políticos no que diz com o incremento dos direitos em si mesmos considerados e também de seus próprios destinatários (...)." 
vice-presidente, senadores e deputados nacionais. Ressalte-se que há, todavia, um projeto de lei em trâmite no Congresso argentino, com o objetivo de modificar o Código Eleitoral (Lei 19.945), permitindo que possam votar estrangeiros com mais de dois anos de residência permanente em território argentino.

Contudo, note-se que na legislação de todas as vinte e três províncias argentinas, assim como na Capital Federal, há normas que permitem aos estrangeiros o exercício do direito de voto ${ }^{5}$, sendo este direito, entretanto, restrito a eleições municipais e, em algumas províncias, também a eleições provinciais. 6

\section{Paraguai}

Nos termos do artigo 120 da Constituição do Paraguai, estrangeiros radicados no país possuem a mesma capacidade eleitoral ativa dos cidadãos paraguaios, todavia somente em eleições municipais. Deste modo, assim como na Argentina, fica vedado o voto de estrangeiros nas eleições para cargos de esfera nacional.

\section{Uruguai}

A Carta Magna uruguaia, em seu artigo 78, garante o direito ao voto a homens e mulheres não nacionais, sem necessidade de requisição da nacionalidade uruguaia, desde que de boa conduta e com família constituída no Uruguai, e que possuam capital ou propriedade no país, ou que desempenhem alguma ciência, arte ou indústria no país, e que tenham residência habitual de pelo menos 15 anos em solo uruguaio.

\section{Chile}

De acordo o artigo 14 da Constituição chilena, os estrangeiros que vivam no país por mais de cinco anos, desde que cumpridos os requisitos exigidos aos cidadãos chilenos, poderão exercer plenamente o direito ao voto.

\footnotetext{
${ }^{5}$ FERREIRA RUBIO, Delia M. El sistema electoral em la Argentina. In: JACKISCH, Carlota (org.). Sistemas electorales y sus consecuencias políticas. Buenos Aires: Konrad-Adenauer Stiftung, 1997. p.153. "En virtud del sistema federal argentino, las províncias son autónomas y, por lo tanto, se dan sus autoridades y establecen la forma em que han de ser electas."

${ }^{6}$ MOREIRA, Carlos. Sufragio Transnacional: La experiência del voto de los extranjeros em Argentina. In: In: Revista Encrucijada Americana, ano 5, n.2. Departamento de Ciencia Política y Relaciones Internacionales - Universidad Alberto Hurtado. Santiago de Chile: Marzo, 2013.
} 


\section{Brasil}

Apesar dos inegáveis avanços que a Carta Magna de 1988 no campo dos direitos fundamentais e de cidadania ${ }^{7}$, de acordo com o parágrafo $2^{\circ}$ do artigo 14 da Constituição da República, estrangeiros não podem alistar-se como eleitores no Brasil.8 A única exceção a esta regra está prevista no parágrafo 1ํ do artigo 12 da Carta Magna, estendendo o direito ao voto aos portugueses com residência permanente no País, se houver, em Portugal, reciprocidade em favor de brasileiros. ${ }^{9}$ Frise-se que tal direito, todavia, não é automaticamente exercido pelos cidadãos portugueses, uma vez que devem primeiramente fazer uma solicitação neste sentido ao Ministério da Justiça e, tendo seu pedido deferido através de portaria, realizar a inscrição no Tribunal Regional Eleitoral competente.

Há, contudo, uma proposta de emenda constitucional, a PEC 25/2012, de autoria do Senador Aloysio Nunes Ferreira, que estende aos estrangeiros com residência permanente no país o direito ao voto no Brasil.

\section{Conclusões}

As legislações dos países do Cone Sul tratam o tema do voto de estrangeiros de maneira muito distinta. Enquanto no Chile os estrangeiros que vivem no país por mais de cinco anos tem pleno direito de voto, o Uruguai exige ao menos 15 anos de residência para garantir este direito. Na Argentina e no Paraguai os não nacionais podem votar, mas não em eleições de âmbito nacional. 0 Brasil, como vimos, é o único país da região que impede de todas as formas o voto dos estrangeiros, com a ressalva feita aos cidadãos portugueses, nos termos do parágrafo $2^{\circ}$ do artigo 14 de nossa Constituição.

Deste modo, parece-nos importante estender aos estrangeiros que aqui fixem residência o direito ao voto, uma vez que a inclusão eleitoral, segundo os ensinamentos

\footnotetext{
7 BARROSO, Luis Roberto. $O$ Direito Constitucional e a efetividade de suas normas. 9a ed. São Paulo: Renovar. p.41. "É inegável que a Constituição de 1988 tem a virtude de espelhar a reconquista dos direitos fundamentais, notadamente os de cidadania e os individuais, simbolizando a superação de um projeto autoritário, pretensioso e intolerante que se impusera ao País."

${ }^{8}$ SILVA TELLES, Olívia Raposo da. Direito Eleitoral Comparado. Saraiva: IDPE, 2009. p.8. "(...) o primeiro requisito para a plenitude do exercício dos direitos políticos é a nacionalidade brasileira (...)"

${ }^{9}$ MORAES, Alexandre de. Constituição do Brasil interpretada e legislação constitucional. São Paulo: Atlas, 2007. p.506. (...) importante salientar que os portugueses equiparados, nos termos do art.12, parágrafo 1으, também poderão exercer direitos políticos."
} 
de GOMES DA SILVA, é um processo ainda em construção, a ser realizado pelo Estado e pela sociedade, de modo a fortalecer os pilares de nossa democracia. ${ }^{10}$

\section{Referências Bibiográficas}

BARROSO, Luis Roberto. $O$ Direito Constitucional e a efetividade de suas normas. 9a ed. São Paulo: Renovar.

CERQUEIRA, Thales Tácito P.L. de Pádua. Direito Eleitoral Brasileiro. 3 ${ }^{a}$ ed. Belo Horizonte: Del Rey, 2004.

CONSTITUCIÓN DE LA REPÚBLICA DE CHILE. Disponível em: http://www.leychile.cl/Navegar?idNorma=242302_ - Consultado em 03 de abril de 2013.

CONSTITUCIÓN DE LA REPÚBLICA ORIENTAL DEL URUGUAY. Disponível em: http://www.parlamento.gub.uy/constituciones/const004.htm - Consultado em 03 de abril de 2013.

CONSTITUCIÓN DE LA REPÚBLICA DEL PARAGUAY. Disponível em: http://www.constitution.org/cons/paraguay.htm - Consultado em 03 de abril de 2013.

CONSTITUCIÓN NACIONAL DE LA NACIÓN ARGENTINA. Disponível em:http://www.senado.gov.ar/web/interes/constitucion/cuerpo1.php Consultado em 03 de abril de 2013.

FERNANDEZ, Anibal. Proyectos. http://www.anibalfernandez.com.ar/index.php/te-lodigo-yo-220/proyectos-de-ley-de-anibal-fernandez/1044-voto-para-extranjeros

PALACIOS, Ana Delicado. Qué países permiten votar a los extranjeros. In: http://america.infobae.com/notas/57613-Que-paises-permiten-votar-a-losextranjeros

RUBIO, Delia M Ferreira. El sistema electoral en la Argentina. In: JACKISCH, Carlota (org.). Sistemas electorales y sus consecuencias políticas. Buenos Aires: KonradAdenauer Stiftung, 1997.

SILVA, Paulo Thadeu Gomes da. Inclusão eleitoral e efetivação dos direitos políticos. In: Temas de Direito Eleitoral no século XXI. Brasília: ESMPU, 2012.

MORAES, Alexandre de. Constituição do Brasil interpretada e legislação constitucional. São Paulo: Atlas, 2007.

MOREIRA, Carlos. Sufragio Transnacional: La experiência del voto de los extranjeros em Argentina. In: Revista Encrucijada Americana, ano 5, n.2. Departamento de Ciencia Política y Relaciones Internacionales - Universidad Alberto Hurtado. Santiago de Chile: Marzo, 2013.

10 GOMES DA SILVA, Paulo Thadeu. Op. Cit. p.63. "Inclusão eleitoral, na qualidade de espécie do gênero inclusão (...) é sempre um trabalho em progresso a ser realizado pelo Estado e pela sociedade, E pode se concretizar tanto pelo sistema jurídico quanto pelo sistema político." 
NUNES, Aloysio. Direito de o estrangeiro votar. Disponível em: http://www.aloysionunes.com/imprensa/direito-de-votar-ao-estrangeiro/ Consultado em 06 de maio de 2013.

SENADO FEDERAL. PEC 25/2012. Disponível em: http://www.senado.gov.br/atividade/materia/detalhes.asp?p_cod_mate=105568 Consultado em 04 de abril de 2013.

TELLES, Olívia Raposo da Silva. Direito Eleitoral Comparado. Saraiva: IDPE, 2009. 